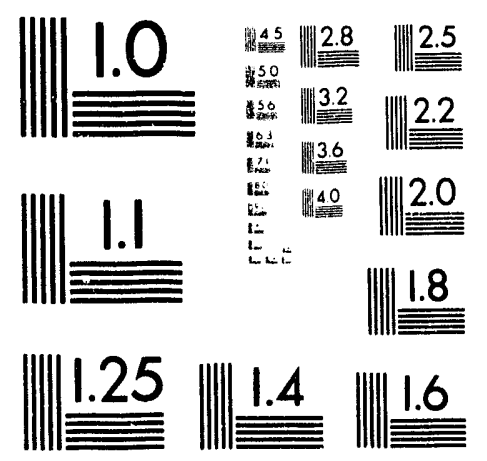



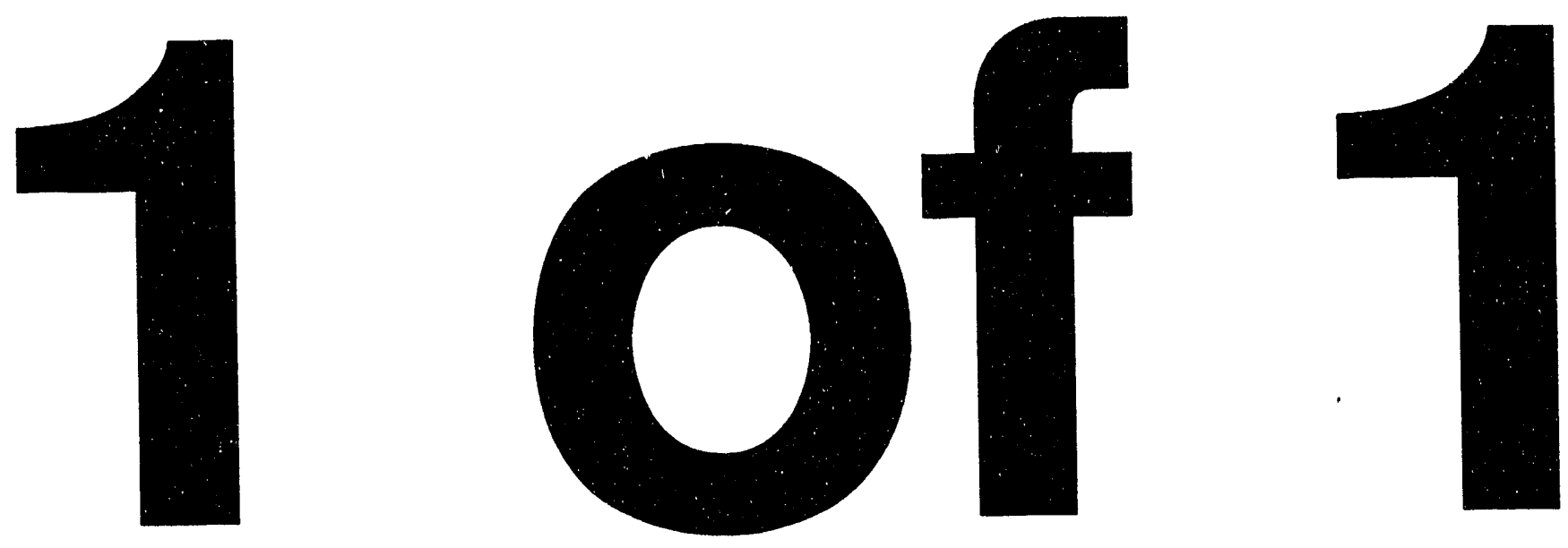


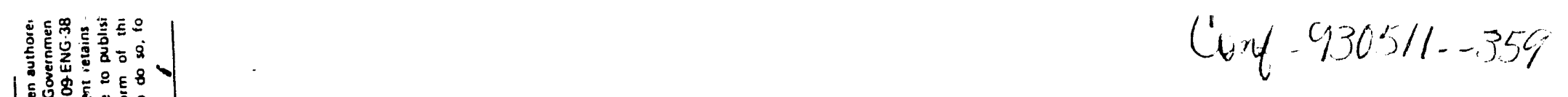

\title{
Operational Status of the Uranium Beam Upgrade of the ATLAS Accelerator
}

\author{
R.C. Pardo, L.M. Bollinger, J.A. Nolen, K.W. Shepard, P. Billquist, J.M. Bogaty, B.E. Cliff, \\ R. Harkewicz, F.H. Munson, J. E. Specht, and G.P. Zinkann \\ Argonne National Laboratory \\ 9700 S. Cass Avenue, Argonne, II 60439-4843 USA
}

\section{Abstract}

The Positive-Ion Injector (PII) for ATLAS is complete. First beams from the new injector have been accelerated and used for experiments at ATLAS. The PII consists of an ECR ion source on a 350-kV platform and a low-velocity superconducting linac. The first acceleration of uranium for the experimental program has demonstrated that the design goals of the project have been met. Since the summer of 1992, the new injector has been used for the research program approximately $50 \%$ of the time. Longitudinal beam quality from the new injector has been measured to be significantly better than comparable beams from the tandem injector. Changes to the mix of resonators in the main ATLAS accelerator to match better the velocity profile for heavy beams such as uranium are nearly complete and uranium energies up to $6.45 \mathrm{MeV}$ per nucleon have been achieved. The operating experience of the new ATLAS facility will be discussed with emphasis on the measured beam quality as well as achieved beam energies and currents.

\section{INTRODUCTION}

The ATLAS Positive-Ion Injector (PII) project was a development project with a goal of providing $6 \mathrm{MeV} /$ nucleon beams of uranium ions as well as higher energies of other ions. ATLAS[1], the world's first application of RF superconducting technology for heavy-ion acceleration, was originally designed to use an existing electrostatic tandem accelerator as the injector for the superconducting linac. This injector was limited to providing beams with $A \leq 100$ due to stripper foil lifetimes and the total available voltage.

The Positive-Ion Injector[2,3] was proposed in 1985 to solve the limitation on ATLAS performance imposed by this tandem injector. The project is now complete and has been operating as an integral part of the ATLAS facility since April, 1992. During the past year, the new PII has met all of its design goals and in a number of important areas now routinely exceeds those goals. The specific goal of providing uranium beams at energies in excess of $6 \mathrm{MeV} / \mathrm{A}$ was achieved on February 9, 1993 when a beam energy of 6.45 MeV/A (1535.1 MeV) was achieved. Beam currents in excess of $4 \mathrm{pnA}$ at $6 \mathrm{MeV} / \mathrm{A}$ have been delivered to target during more recent runs.

In the remainder of this paper, specific performance parameters are reported and compared to expected performance. Near term future improvement plans are also discussed.

\section{SYSTEM DESCRIPTION}

The PII consists of two major components. An electron cyclotron resonance (ECR) ion source on a $350-\mathrm{kV}$ platform provides high charge-state ions (charge-to-mass ratio $(Q / A) \geq 0.1)$ to a new independently-phased superconducting resonator linac with a total effective voltage of approximately $12 \mathrm{MV}$. A floor plan of the PII is shown in Figure 1.

The PII ECR ion source[4] is the first ECR source to operate on a high voltage platform. Attention was given to minimizing power consumption while maintaining good performance for high charge-state ion production and to provide maximum flexibility for the production of beams from solids. The source operates with an RF frequency of 10 $\mathrm{GHz}$. The high voltage platform design provides for the necessary source and beam transport utilities while maintaining a total voltage stability of $\Delta V / V \approx 10^{-4}$. Routine performance of the source for uranium ions using $\mathrm{UO}_{2}$ source material is shown in Figure 2.

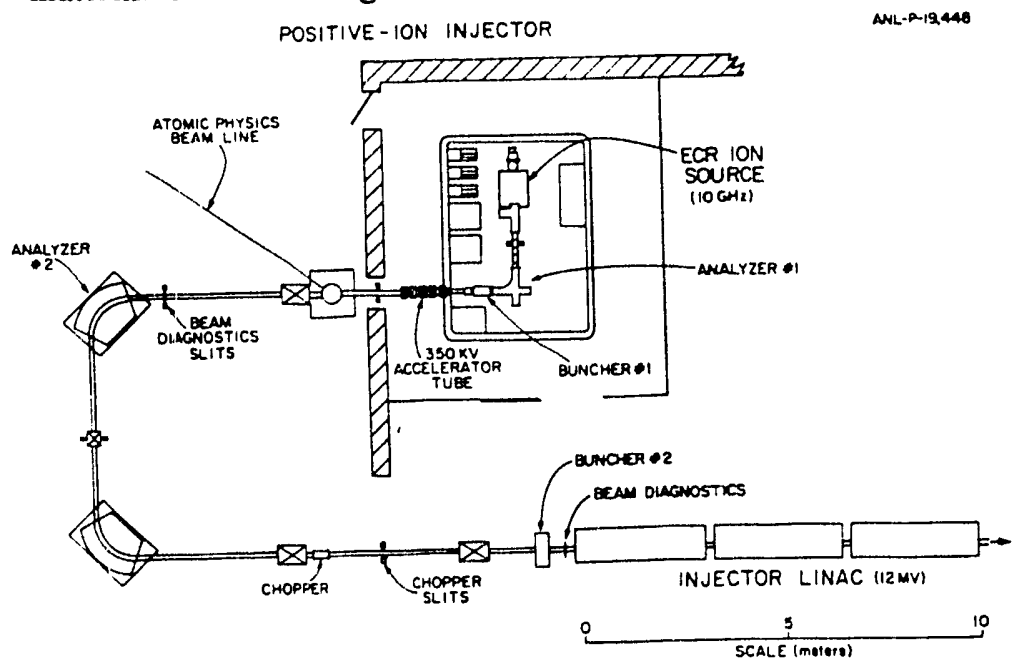

Fig. 1. Major elements of the Positive-Ion Injector.

The PII linac consists of 18 niobium superconducting quarter-wave resonators[5] (see Figure 3) of four different matched velocities. Superconducting solenoids are interspersed among the resonators for transverse focusing. The first resonator in the PII is designed for a matched velocity of $0.009 \mathrm{c}$ for ions with $\mathrm{Q} / \mathrm{A}=0.1$. The average accelerating gradient of the resonators in the PII linac section during recent operation has been $3.6 \mathrm{MV} / \mathrm{m}$, corresponding to a surface field of $18 \mathrm{MV} / \mathrm{m}$. This performance is a significant improvement over the design accelerating gradient of approximately $3 \mathrm{MV} / \mathrm{m}$. Operation at these gradients has been reliable and trouble-free. Average power into the helium system under these conditions is about 6.5 watts per

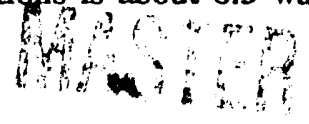




\section{DISCLAIMER}

This report was prepared as an account of work sponsored by an agency of the United States Government. Neither the United States Government nor any agency thereof, nor any of their employees, makes any warranty, express or implied, or assumes any legal liability or responsibility for the accuracy, completeness, or usefulness of any information, apparatus, product, or process disclosed, or represents that its use would not infringe privately owned rights. Reference herein to any specific commercial product, process, or service by trade name, trademark, manufacturer, or otherwise does not necessarily constitute or imply its endorsement, recommendation, or favoring by the United States Government or any agency thereof. The views and opinions of authors expressed herein do not necessarily state or reflect those of the United States Government or any agency thereof. 
resonator. An important contributor to this level of resonator performance is the significant improvement in the performance of the fast-tuning phase stabilization system (VCX) for these resonators[6].

The goal of the PII design was to develop a lowvelocity linac system which combines broad Q/A ratio acceptance, excellent beam quality, increased beam current, and high total efficiency. These goals have been fully realized in the achieved performance of the PII.

\section{OPERATING EXPERIENCE}

The complete ATLAS-PII system began providing beams for the research program in April, 1992 and the facility became fully operational in July, 1992. Since then the PII has been used as the ATLAS injector more than $50 \%$ of the time and now nearly $80 \%$ of all beam time is provided by the PII. Nearly 1800 hours of research beam time has been provided during the past year. The system has been quite reliable with beam on-target $92 \%$ of the scheduled experimental time. Table I lists the beams which have been provided to the research program during that period.

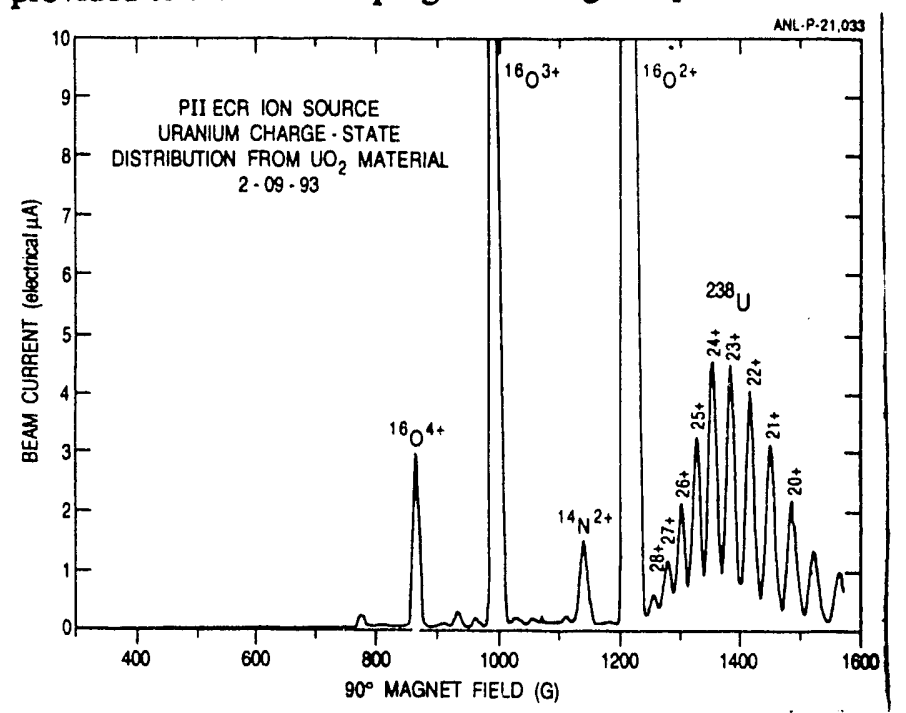

Fig. 2. Uranium charge-state distribution from ECR source.

Table I

Properties of Beams Accelerated During First Year of PII Operation

$\begin{array}{lccc}\text { Ion Species } & \begin{array}{l}\text { PI Exit } \\ \text { Energy } \\ (\mathrm{MeV})\end{array} & \begin{array}{l}\text { Max. ATLAS } \\ \text { Energy Used } \\ (\mathrm{MeV})\end{array} & \begin{array}{c}\text { PII Long. } \\ \text { Emit. }(\pi \\ \mathrm{keV} \cdot \mathrm{ns})\end{array} \\ { }^{20} \mathrm{Ne}^{6+} & 33 & 160 & \\ { }^{27} \mathrm{Al}^{5+} & 45 & 167 & \\ 28,30 \mathrm{Si}^{5,7+} & 43 & 161 & 12 \\ { }^{36,40} \mathrm{Ar}^{10,9} & 62,69 & 260 & 8 \\ { }^{78,83} \mathrm{Kr}^{16,15 \& 30} & 125 & 450,723 & \\ { }^{92,100} \mathrm{Mo}^{15} & 153 & 440 & \\ 132,136 \mathrm{Xe}^{18} & 178 & 752 & 62 \\ { }^{208} \mathrm{~Pb}^{24839} & 248 & 1018 & 20 \\ { }^{238} \mathrm{U}^{24839} & 300 & 1535 & 39\end{array}$

The longitudinal emittance (the area occupied in energy-time space) of beams from the Positive-Ion Injector was expected to be improved over that possible from the tandem injector, largely because of the reduced need for stripping for medium mass beams and improved beam transport optics. The transverse beam emittance was expected to be similar to that of beams from the tandem injector. Those expectations have been met. The longitudinal emittances of a number of the beams from the PII have been measured and are generally one half the values for beams of similar mass from the tandem. Table I lists the longitudinal emittance of a number of PII beams. The quoted value is the product of half-width half-maximum in units of $\pi$ $\mathrm{keV} \cdot \mathrm{ns}$.

\section{URANIUM BEAM DEVELOPMENT}

The first acceleration of uranium with the new Positive-Ion Injector(PII) of ATLAS was successfully accomplished during the week of July 27,1992 . A beam of $300-600$ electrical nanoamps ${ }^{238} U^{28+}$ was provided by the ECR ion source and accelerated by the PII linac to $293 \mathrm{MeV}$. This beam was stripped to a $42+$ charge state and further accelerated to $1363 \mathrm{MeV}$ (5.7 MeV per nucleon) by the ATLAS linac. Beam current after stripping and acceleration was $6 \mathrm{enA}$ at the exit of the accelerator (for $300 \mathrm{enA}$ injected). A second uranium run occurred in the first week of September.

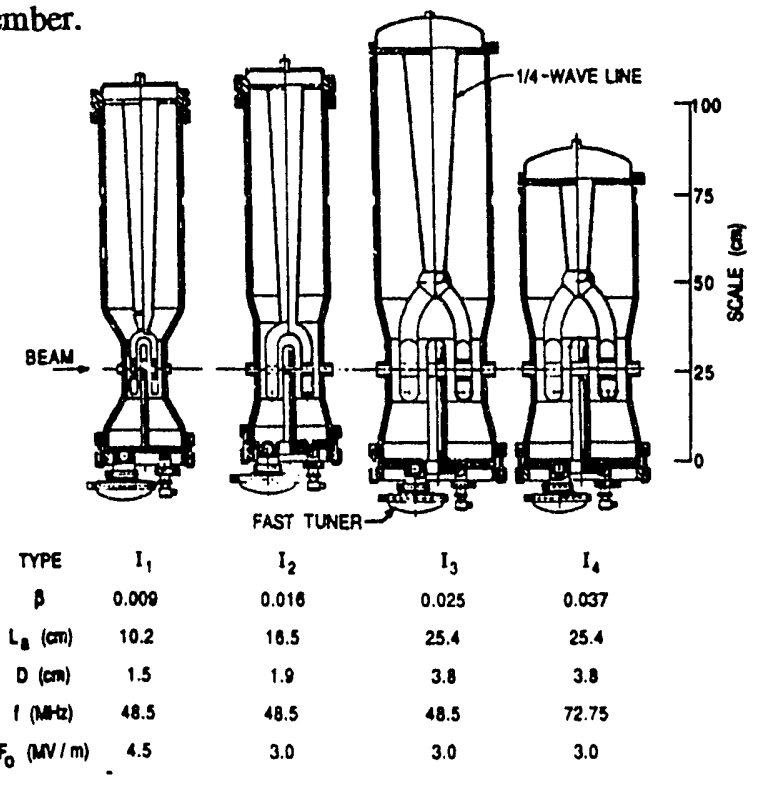

Fig. 3. Resonators used in the Positive-Ion Injector..

A number of important techniques were demonstrated and refined in these early runs. The most important of these was the highly surcessful tuning of the 'booster' portion of the ATLAS linac with an analog beam from the tandem. In this case ${ }^{34} S^{6+}$, which has the same charge-to-mass ratio as ${ }^{238} \mathrm{U}^{42+}$, was used. This analog beam technique is necessary because a number of charge states are now injected into the 'booster' portion of the linac and so, 
tuning of a single selected charge state is not possible for this section of the linac before completion of the charge-state selector.

During the Fall and Winter, 1992 a major upgrade project to the existing ATLAS linac took place in order to achieve the goal of reliable operation of $6 \mathrm{Mr}$.V/A uranium with beams current of 5-10 pnA. Six of the resonators in the ATLAS linac which had a matched velocity of approximately $0.15 \mathrm{c}$ were replaced with resonators whose matched velocity was $0.1 \mathrm{c}$. This modification results in a significantly improved match to the velocity profile of low charge-to-mass ratio beams such as uranium. In addition, the improved fast tuner design was implemented for those devices.

The results of the improvements implemented in this period resulted in achieving a uranium beam energy of 6.45 MeV/A during February, 1993 with approximately 1pnA on target. Additional improvements in the system have now resulted in subsequent runs in March and May yielding beam currents of 5-7 pnA at $6.45 \mathrm{MeV} / \mathrm{A}$ for the experimental program. The increase in beam current was due to the use of lower charge states from the ECR ion source and from the stripping distribution. In the most recent run in May, 1993, charge state $24+$ was selected from the source while charge state $39+$ was selected from the stripping foil. The analog beam used for this situation was ${ }^{60} \mathrm{Ni}^{10+}$.

Stripper foil lifetime and charge-state distributions, which are very important to the performance of ATLAS for these very heavy beams, have been studied. Both carbon foils and self-supporting beryllium foils have been used. Beryllium foils exhibit a charge-state distribution peaked toward higher charge states as shown in Figure 4. This effect has been previously reported[7] and is due to reduced recombination cross-sections for the 'low- $Z$ ' materials. Foil lifetime for carbon striping uranium at $300 \mathrm{MeV}$ have been measured to average 175 pnA-hours. Beryllium foil lifetime has not been as good with an average of 75-100 pnA-iours.

\section{Uranium Charge State Distribution} In $\mathrm{Be}$ and Carbon Foils $2290 \mathrm{MeV}$

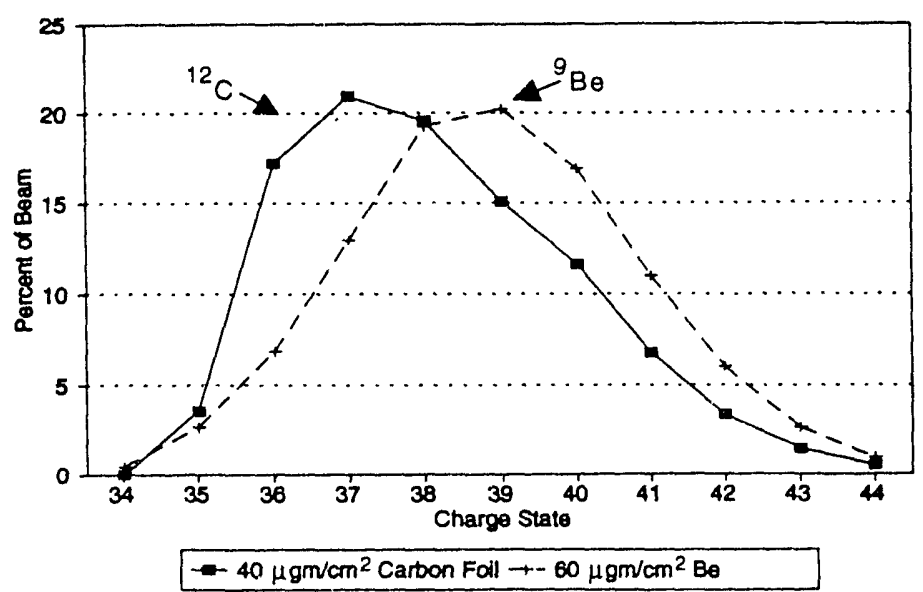

Fig 4. Stripped charge-state distributions from beryllium and carbon foils at $290 \mathrm{MeV}$.
Beam transmission through the PII linac was excellent for uranium. The total beam transmission through the PII linac was as bigh as $63 \%$, including the bunching efficiency. Typical bunching efficiency is $60-70 \%$, indicating that the transport efficiency of bunched beam through the PII is greater than $90 \%$. Transmission through the ATLAS accelerator averaged $80-85 \%$. The normalized transverse emittance of the uranium and lead beams has been measured to be between $0.2-0.5 \pi \mathrm{mm}-\mathrm{mr}$. This is two to three times greater than expected. We are investigating the cause of this emittance growth.

\section{CONCLUSION AND SHORT TERM PLANS}

The initial operation of the new PII-ATLAS system has met all of the project goals. Resonator and ion source performance meet or exceed all the specific goals. The system reliability, even during these early operational runs has been excellent.

A new charge-state selector system, which will select and deliver to the ATLAS linac a single charge-state from the PII stripper, is expected to be installed in the Fall, 1993. This will eliminate the need to tune the 'bonster' section of the linac with a 'guide' beam and simplify setup for the heaviest of beams.

A new wet engine will be installed in September, 1993 on one of the refrigerators in the system to provide increased refrigeration capacity and to improve reliability. Resonator performance improvements may also be realized.

This research was supported by the US D.O.E., Nucl. Phys. Div., contract W-31-109-ENG-38.

\section{REFERENCES}

[1] J. Aron, et al., Proceeding of the 1984 Linear Accelerator Conference, Seeheim, W. Germany, May 1984, GSI Report GSI-84-11, pp. 132 (1984).

[2] L. M. Bollinger and K. W. Shepard, Proceeding of the 1984 Linear Accelerator Conference, Seeheim, W. Germany, May 1984, GSI Report GSI-84-11, pp. 217 (1984).

[3] R. C. Pardo, L. M. Bollinger, and K. W. Shepard, Nucl. Instrum. and Methods, B24/25, 746 (1987).

[4] R. C. Pardo, Nucl. Instrum. and Methods, B40/41, 1014 (1989).

[5] K. W. Shepard, et al., Pioceedings of the 1989 IEEE Particle Accelerator Conference, Chicago, $\mathrm{L}, \mathrm{March}$, 1989, pp. 974 (1989).

[6] N. Added, B. E. Clifft, and K. W. Shepard, Proceeding of the 1992 Linear Accelerator Conference, Ottawa, Ont., August, 1992, pp. 181 (1992).

[7] J.P. Rozet, etal., J. Phys. B., 22, 33(1989). 

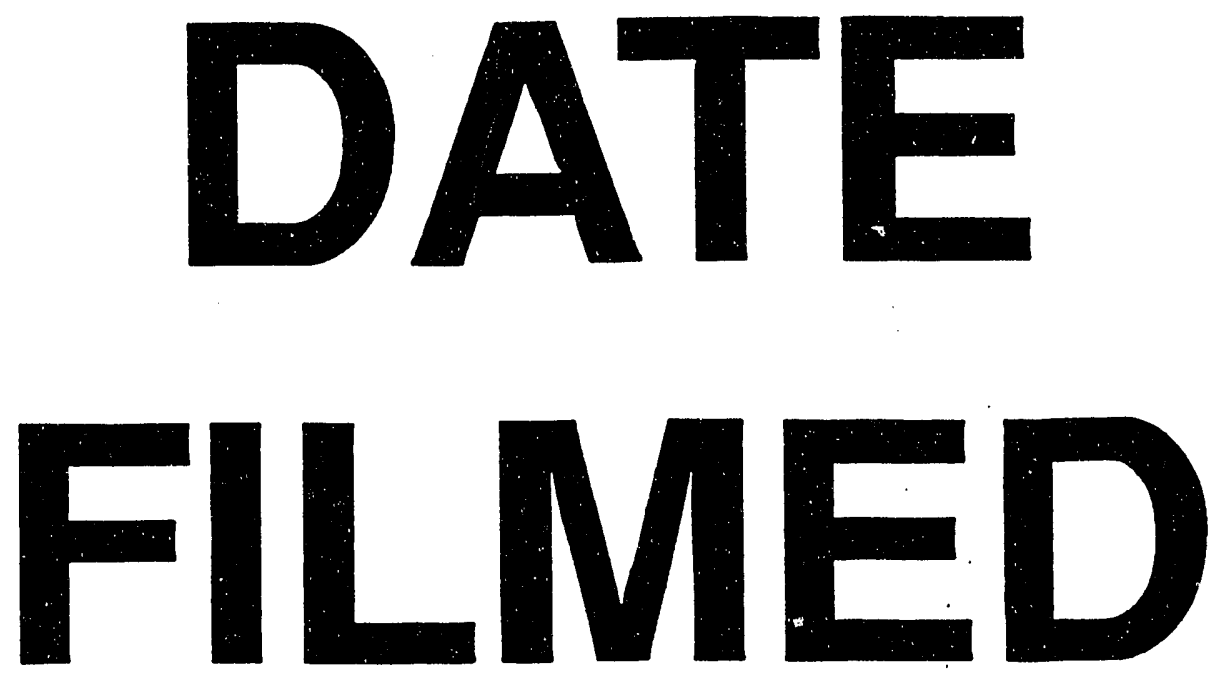

$10 / 13 / 93$
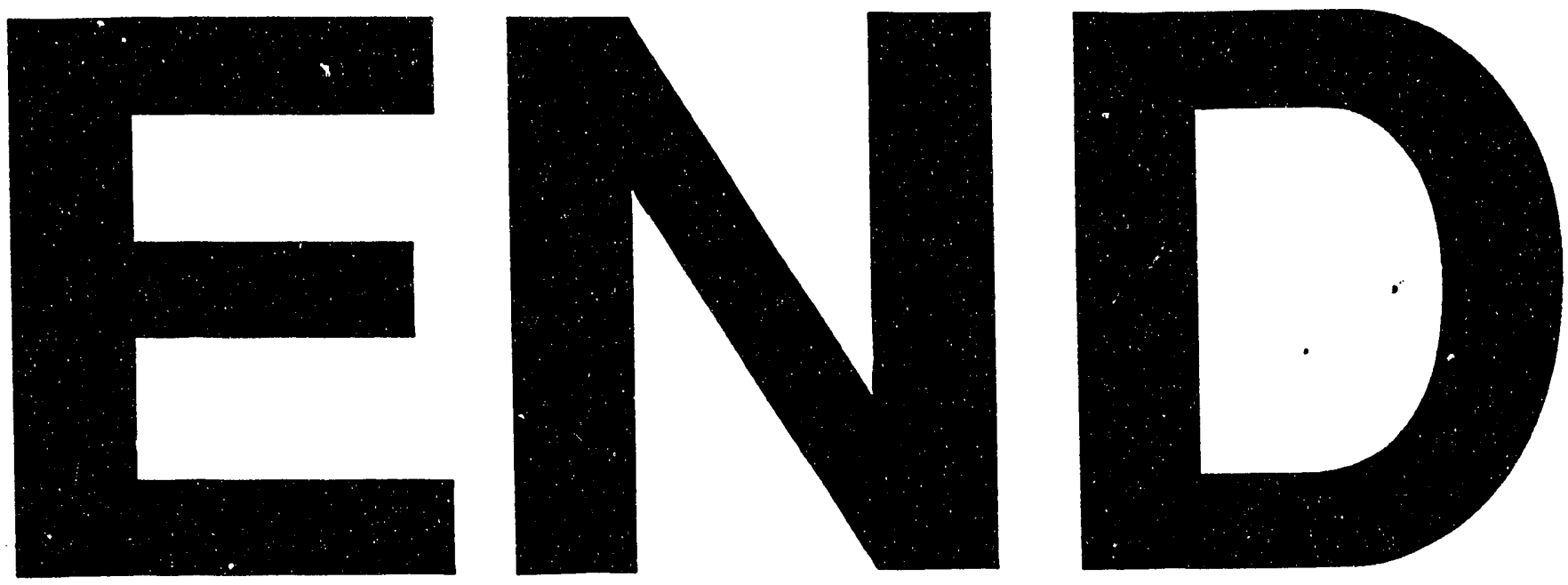
